Session 3151

\title{
Developing an Ecological Engineering Curriculum
}

\author{
Scott D. Bergen, Susan M. Bolton, James L. Fridley \\ University of Washington
}

\begin{abstract}
This paper describes efforts to develop an Ecological Engineering curriculum at the University of Washington. Ecological engineering is the design of sustainable systems consistent with ecological principles that integrate human society with its natural environment for the benefit of both. Graduates will be able to practice design with an appreciation for the relationship of organisms (including humans) with their environment, and the constraints on design imposed by the complexity, variability and uncertainty inherent to natural systems. Students educated as ecological engineers will be prepared to work on pressing environmental problems such as:

1. The design of ecological systems (ecotechnology) as an alternative to manmade/energy intensive systems to meet various human needs (for example, constructed wetlands for wastewater treatment).

2. The restoration of damaged ecosystems and the mitigation of development activities.

3. The management, utilization, and conservation of natural resources.

4. The integration of society and ecosystems in built environments (for example, in landscape architecture, urban planning, and urban horticulture applications).
\end{abstract}

We discuss our concept of the definition and scope of ecological engineering, and the knowledge areas and skills that could be included in a university curricula. Specific attention is given to the principles of ecology that will influence ecological engineering design practice. We also note organizational challenges posed by working with faculty and administration from many disciplines, attracting students, research funding and external partnerships, and seeking ABET accreditation.

\section{Introduction}

The emerging practice of ecological engineering grows out of the failure of past engineering practice to provide for human welfare while at the same time protecting the natural environment from which goods and services are drawn. It recognizes that humanity is inseparable and dependent on natural systems, and that growing worldwide population and consumption has damaged, and will increasingly pressure, global ecosystems. Sustaining human society requires engineering design practices that protect and enhance the ability of ecosystems to perpetuate themselves while continuing to support humanity.

Ecological engineering is the design of sustainable systems consistent with ecological principles that integrate human society with its natural environment for the benefit of both. This paper 
describes efforts at the University of Washington to develop an ecological engineering curriculum, an educational experience that will integrate ecological science with engineering design principles.

Many scientists working in environmental fields are, in fact, practicing engineering as they take scientific principles and use them to address specific problems. However, very few scientists have had any engineering training, and there is little evidence of accepted engineering design methods being followed in this 'applied ecology.' Additionally, engineers are increasingly undertaking design problems in which a solid scientific understanding of natural systems is needed. Our proposed curricula will not teach ecologists a little engineering, nor engineers a little ecology. We envision a new engineering discipline with ecological science as its basis. Graduates will be able to practice design with an appreciation for the relationship of organisms (including humans) with their environment and the constraints on design imposed by the complexity, variability and uncertainty inherent to natural systems. This approach could lead to a new paradigm for engineering design.

Ecological engineering has been defined in a number of ways, so we begin this paper with a look at past definitions and propose a new definition. We discuss the current and potential scope of ecological engineering practice, identifying where graduates of a university might find employment. Ideas for developing a curriculum are presented with attention given to engineering design as it relates to ecology. Finally, we address some organizational issues related to working with faculty and administration from many disciplines, attracting students, research funding and external partnerships, and seeking ABET accreditation.

\section{Definitions}

As a relatively new field, effort continues to be spent in defining the scope and purpose of ecological engineering. Various authors have put forward definitions for ecological engineering, and these definitions reflect the particular aspects of the practice that they feel are critical. The term itself is attributed to H. T. Odum who defined ecological engineering as, "Environmental manipulation by man using small amounts of supplementary energy to control systems in which the main energy drives are still coming from natural sources". ${ }^{1}$ Mitsch and Jørgensen define the practice as, "the design of human society with its natural environment for the benefit of both". 2 This definition was slightly refined to read, "The design of sustainable ecosystems that integrate human society with its natural environment for the benefit of both". ${ }^{3}$ Mitsch lays out the goals of ecological engineering as being the restoration of human disturbed ecosystems and the development of new sustainable ecosystems that have human and ecological value. In the latter case, ecosystems are designed and created to solve human problems.

Harnessing the self-design or self-organizational properties of natural systems is a key component to ecological engineering. ${ }^{1,4}$ In a constructed ecosystem, humans are likely responsible for providing the initial components and structure of the system, as well as influencing the larger environment that the ecosystem connects to. Once created, however, nature takes over and the composition and structure become those best suited to respond to the 
condition imposed on the system. Little energy is expended by humans to maintain a particular ecosystem state.

The term ecological engineering is also widely used in China to define "a specially designed system of production processes in which the principles of the species symbiosis and the cycling and regeneration of substances in an ecological system are applied while adopting the systems engineering technology and introducing new technologies and excellent traditional production measures to make a multi-step use of substance". 5 The experience in China with ecological engineering is similar in that the focus is on working with ecological processes in systems designed to meet human needs (such as pisciculture). A significant difference, however, is that the Chinese do not rely heavily on self-design and often there is substantial human intervention to maintain the system. ${ }^{6}$

In the introduction, we present a definition for ecological engineering that is a slightly modified version of Mitsch's:

Ecological engineering is the design of sustainable systems consistent with ecological principles that integrate human society with its natural environment for the benefit of both.

We feel that this definition has a number of key elements that should be in any definition of the discipline:

1. That the practice is based on ecological science,

2. That ecological engineering is defined broadly enough to include all types of ecosystems and potential human interactions with ecosystems,

3. That the concept of engineering design is included,

4. That there is an acknowledgment of an underlying value system.

The first point is the most fundamental. Ecological engineering could be defined by its science base, by its application, or by both. Perhaps unlike civil engineering, which is more clearly defined by its applications than the science that informs it, ecological engineering, to be truly a unique engineering discipline, must be based on ecology. It could perhaps be more simply defined as: The engineering discipline with ecology as its fundamental science base. In this case the application of ecological engineering could stretch beyond working with ecosystems and influence all engineering practice, representing a new paradigm for engineering design. However, the question of whether there is a way of practicing engineering that is significantly different from current practices, and is based on an understanding of ecology, remains. This has not been shown, but we believe the answer is yes.

The second principle above relates to application. While ecological engineering may represent a new way of engineering, its most obvious application is to engineering as it relates to human interaction with ecosystems. The literature focuses primarily on created and restored ecosystems, but leaves out the broad and important area of societal interaction with existing, and not necessarily degraded, ecosystems. 
Engineering educators are placing renewed importance on teaching design skills to students. Explicitly using the word design in our definition makes clear that it is the principle activity of engineering. Successful engineering design requires, in part, adherence to a formal methodology. Much has been written about engineering design as it relates to engineering in general. It remains to be shown if traditional engineering practice can solve ecological engineering problems. Given that traditional practices contributed to environmental degradation, methodological issues should be considered. We will discuss design education later.

The last principle, regarding values, is perhaps the most sticky for two reasons. The first is whether the definition of an engineering activity should have a value system attached to it. We believe it should because it is naive to assume that we can separate our motivation for practicing ecological engineering from our actions. Therefore, the motivations should be made explicit. There is also precedent for stating values found in the fact that engineering and other professional societies generally adopt a code of ethics to guide their membership. A code of ethics should eventually be adopted for ecological engineering.

The second sticking point then, is if we decide to include a statement of values in the definition, what values should we express? This is a hot topic, but concepts such as human benefit, sustainability, and ecological health and integrity are often mentioned in the literature. For now, the statement of values in the definition of ecological engineering will be most accepted if it appeals to a plurality of value frameworks. ${ }^{7}$

\section{Program Scope}

We have defined ecological engineering broadly and advocate its application to a number of problem areas. Potential applications include:

1. The design of ecological systems (ecotechnology) as an alternative to manmade/energy intensive systems to meet various human needs (for example, constructed wetlands for wastewater treatment).

2. The restoration of damaged ecosystems and the mitigation of development activities.

3. The management, utilization, and conservation of natural resources.

4. The integration of society and ecosystems in built environments (for example, in landscape architecture, urban planning, and urban horticulture applications).

There exist current methods for dealing with all the applications listed above. We feel, however, that ecological engineering can offer a unique approach to each. The first area of application, ecotechnology, is the most thoroughly discussed to date. It is an application of ecological engineering that has been described as ecological solutions to environmental engineering problems. ${ }^{3}$ The most prevalent example is the treatment of various forms of waste products. Environmental engineering solutions to waste management focus on energy intensive processes such as sewage treatment plants, settling tanks and scrubbers. Ecological engineering addresses the same problem with systems that rely on ecological processes that require minimal energy input from humans (are essentially solar-powered). 
Ecological restoration and development mitigation currently fall under the domain of applied or restoration ecology. Ecological engineering can add to these activities by providing a more formal and structured design method. Attention to the process of design in reports on applied ecology is often missing.

The third application area relates to the management of natural resources. The goal for managing existing systems would be to harvest some benefit from the ecosystem while preserving the health or integrity of the system, not compromising the production of ecological services, and not inducing unexpected changes in the system. Examples of such systems include forest and rangeland ecosystems and fisheries. In the case of forest management we may be interested in harvesting timber from an ecosystem without diminishing the ability of the forest to regenerate, to provide clean water and air, and provide habitat for a range of plant and animal species. Essentially, using the forest with minimal impact to the ecosystem. In the case of fisheries, we may want to harvest some fish without depleting stocks beyond recovery. This would signal a shift toward living off ecological "interest" and not depleting natural "capital". 8 Our extraction level would fall within the noise level of the natural variation of the system. Moving away from spending natural capital given current and probable future pressures on ecosystems is a monumental problem.

The goal of ecological engineering is to better integrate society with its supporting environment. Creating integrated urban and other built environments is a potential application for ecological engineering. Endemic ecosystems are often completely destroyed when dense human populations arrive in an area. Increasing calls for "greening" urban environments, allowing for more of a connection to place and nature in built environments will require design that includes ecology and engineering. Traditional landscape architecture, urban planning, and urban horticulture approaches can be augmented by ecological engineering.

\section{Curriculum}

We stated in the introduction that our vision for an ecological engineering degree program was not to teach engineers a little ecology, nor ecologists engineering design skills. Rather we believe a curriculum that has strong ecology, engineering fundamentals and design components is required.

Figure 1 illustrates the potential knowledge areas and skills relevant to an ecological engineering curriculum. The specific sequence of required course work and electives, and the strategy for fulfilling minimal requirements in a four, or perhaps five, year program need further investigation. The figure shows two paths of knowledge feeding into a capstone design experience. Capstone design projects allow students to synthesize and apply knowledge gained from their course work to solve real world problems in cooperation with local agencies, companies, and other academic programs. Projects for a capstone design course in ecological engineering could include wetland, stream and habitat restoration, mitigation of development projects, and bioremediation projects. 
On the left side of Fig. 1 are curriculum components associated with ecology, and on the right are the traditional components of an engineering degree program. The right side forms an area of study we call sustainable design. As noted previously, we believe ecological engineering design will differ from traditional practices. The design process must be informed by ecological principles including those that follow.

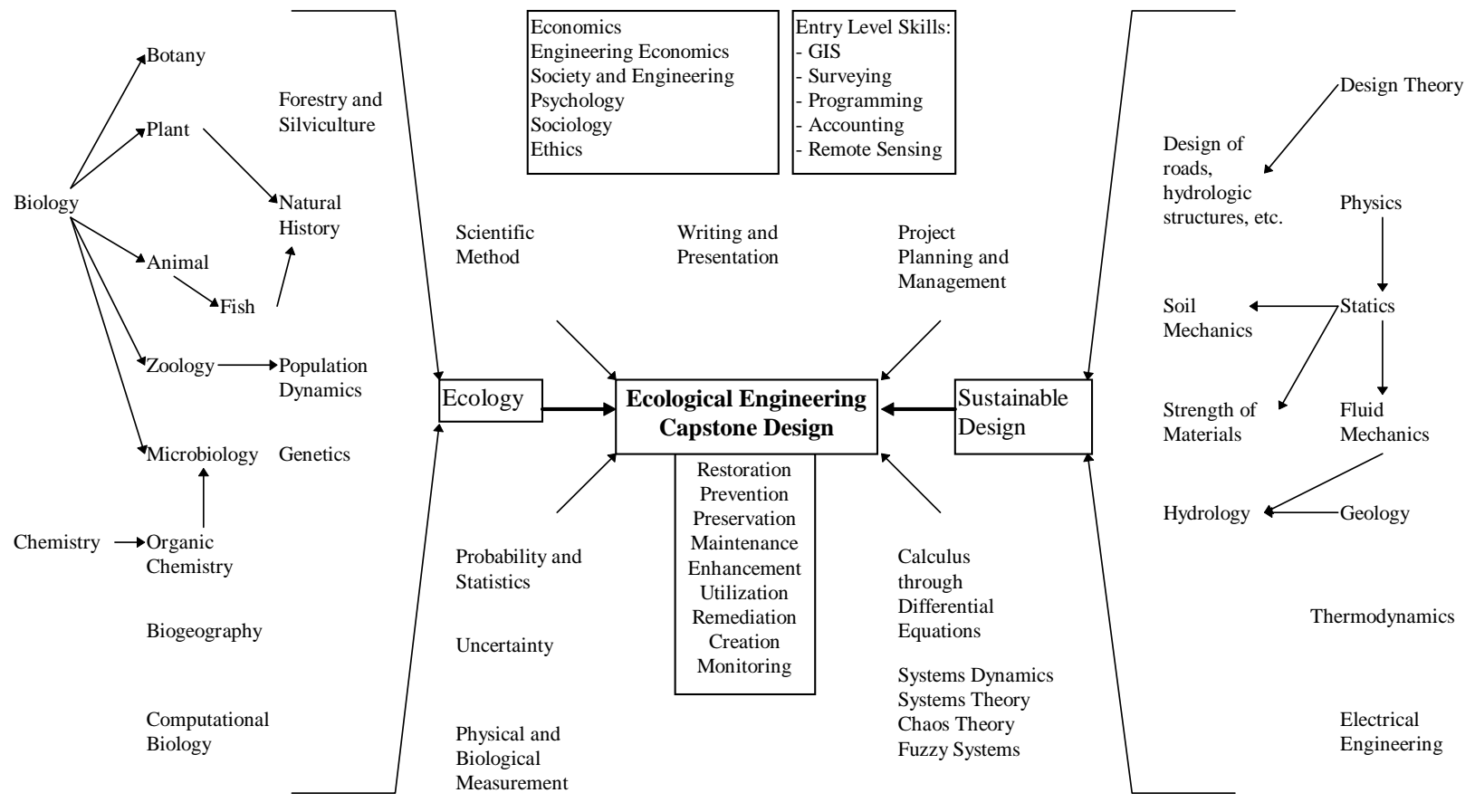

Figure 1. Potential knowledge areas and skills for an ecological engineering curriculum culminating in a capstone design course.

Ecosystems are complex, non-static systems. Significant ecological change is episodic and critical ecosystem processes occur at rates spread over several orders of magnitude, but clustered around a few dominant frequencies. ${ }^{9}$ Ecosystems are heterogeneous, displaying patchy and discontinuous textures at all scales. Ecosystems do not function around a single stable equilibrium. Rather, Holling states that, "destabilizing forces far from equilibria, multiple equilibria, and absence of equilibria define functionally different states, and movement between states maintains structure and diversity." The structure and diversity produced by the large functional space occupied by ecosystems is what allows them to remain healthy, or to persist.

The large functional space required for sustainable ecosystems is directly at odds with traditional engineering design practices that create systems that operate close to a single, chosen equilibrium point. Holling uses this idea to distinguish between what he terms engineering resilience and ecological resilience. ${ }^{9}$ Engineering resilience measures the degree to which a system resists moving away from its equilibrium point and how quickly it returns after a perturbation. Ecological resilience reflects how large of a disturbance an ecosystem can absorb before it changes its structure and function by changing the underlying variables and processes that control 
behavior. The equilibria conditions discussed above for ecosystems exist within the range of ecological resilience.

The distinction between the two types of resilience is important because management policies that force ecosystems to function in a state of engineering resilience lead to a loss of ecological resilience. Systems managed to produce a consistent, high yield of a single variable (such as timber or fish) lose the functional and structural diversity required to remain ecologically resilient. The system is then more susceptible to "failure", where it may lose the ability to produce the same outputs in the future. ${ }^{9}$

Other important principles include the self-organizational or self-designing capacity of ecosystems, built-in redundancy, and the tendency to operate on the edge of chaos. Odum's definition of ecological engineering incorporates the concept of self-organization. ${ }^{1}$ The basic idea is to let nature do all of the work via biological and physical processes with solar radiation as the main energy source for the system. Human input of energy is kept to the minimum amount required to guide the system toward the desired functional range. In the case of an engineered wetland, for example, a wide range of species may be included in the initial construction, but natural processes are allowed to select those best suited for the imposed environment. ${ }^{3}$ In the case of larger systems, such as a forest, the implication is that high energy inputs to control system structure or function are probably counterproductive to the ecological resilience and performance of non-emphasized functions of the system.

Holling refers to redundancy in ecosystems as functional diversity. ${ }^{9}$ A number of species or processes in the system can perform similar functions. If one is impaired then others fill the void contributing to the ecological resilience of the system. The implication here is to maintain diversity in managed systems and alludes to the classic quote from Aldo Leopold, "To keep every $\operatorname{cog}$ and wheel is the first precaution of intelligent tinkering." 10 Protecting diversity also provides insurance against uncertainty.

A final characteristic of natural systems is that they tend to function near the edge of chaos or instability. ${ }^{8,9}$ Systems operating near the edge can take better advantage of evolutionary opportunity. Cairns notes that our current technological systems have coevolved with ecosystems and that introducing chaos into one system will likely lead to chaos in the other.

Successful ecological engineering design must take advantage of the constructive role of instability in natural systems. ${ }^{9}$ Engineered solutions must embody the same principles advocated by Walters for adaptive management, that solutions be considered experimental and be flexible enough to respond to natural and social variability and increasing knowledge. ${ }^{11}$ A strategy consistent with adaptive management is to design safe-fail solutions. As opposed to traditional fail-safe approaches, safe-fail solutions acknowledge that our original functional requirements for a design may not be met or that there may be unexpected results. Failure in this case is not catastrophic. Costanza advocates selecting design alternatives that have the best worst-case outcome. ${ }^{12}$ These strategies help us deal with uncertainty, which is probably the largest single challenge involved with ecological engineering. 
Earlier we noted that ecological engineering design principles could find application in other engineering disciplines. In the same way that ecological engineering represents a new way of practicing design, there is likely a corresponding value in using an ecological model to educate and train engineers. Catalano describes an ecological approach to engineering education that replaces a traditional, Cartesian approach. ${ }^{13}$ An ecological approach acknowledges and capitalizes on the non-linear rather than linear and rational path of learning, the non-dualistic and interdependent relationship between mankind and nature, and student and teacher, and the culturally biased and non-objective quality of education.

\section{Organization and Accreditation}

Formation of an ecological engineering program at the University of Washington is currently under discussion. The University is well situated, academically and geographically, to support an ecological engineering program. Students are increasingly interested in pursuing a course of study that links natural and human systems. Creating an ecological engineering program is a faculty-driven idea. Our goal is to establish an innovative and identifiable curriculum that crosses many disciplinary boundaries, and creates new teaching and research opportunities. Relevant academic expertise at the University of Washington is found in programs including: Biology, botany, civil and environmental engineering, ecosystem science and conservation, fisheries, forest engineering, forest management, landscape architecture, quantitative science, urban design and planning, urban horticulture, and zoology.

Coordinating participation from many departments poses a challenge to program development. Close ties to the College of Engineering are essential, but the program must be given enough latitude to develop and to offer diverse opportunities to students.

Many local, state and federal agencies, and private companies active in the Pacific Northwest undertake projects that will benefit from ecological engineering principles. These agencies and companies can provide employment to program graduates, research grants and cooperation. They will have to be convinced, however, of the value of students trained in the program.

Opportunity also exists to work with other universities and accreditation agencies to define standards for accrediting ecological engineering programs. At this point no standards exist for ecological engineering, and the standards for environmental engineering are too narrow and specific to accept a program of the scope described here. The program can be structured, however, to qualify as a "nontraditional" program under the ABET criteria. There also do not exist standards for certifying ecological engineers as Professional Engineers.

\section{Conclusions}

We are in the early stages of developing an ecological engineering program at the University of Washington, and much work remains. We believe the opportunities for an emerging discipline and educational program are great. As a new field, there is danger of confusion from multiple and competing visions of what ecological engineering is, and the scope of its application. We have attempted to provide an inclusive and broad definition and suggest potential applications 
where an ecological approach to engineering design can augment the efforts of other professionals to solve complicated and pressing problems.

An ecological engineering curriculum should provide solid education in ecology, engineering fundamentals and design. Perhaps the greatest contribution to engineering that the curriculum can make is a new methodology for design, informed by ecology. We have sketched out some of the basic ecological principles that will need to be integrated into design methods. How this will happen and how some of the apparent conflicts with traditional practices will be resolved is unknown, and will likely be an evolutionary process.

A curriculum must also tackle other large issues, not explored here, of uncertainty in design and ethics. Uncertainty can be high and irreducible when dealing with complex natural systems, and will need to be given proper consideration. Under conditions of scientific uncertainty, engineers will participate in making decisions where value systems and ethics play a large role. By examining how values enter into engineering and exploring codes of ethics, educators can prepare students for real world situations.

\section{References}

1. Odum, H. T., W. L. Siler, R. J. Beyers, and N. Armstrong. 1963. Experiments with engineering of marine ecosystems. Publication of the Institute of Marine Science of the University of Texas 9:374-403.

2. Mitsch, W. J. and S. E. Jørgensen. 1989. Introduction to ecological engineering. In: Ecological Engineering: An Introduction to Ecotechnology, W. J. Mitsch and S. E. Jørgensen (eds.). John Wiley \& Sons, NY. p. 3-12.

3. Mitsch, W. J. 1996. Ecological Engineering: A New Paradigm for Engineers and Ecologists. In: Engineering within ecological constraints, P. C. Schulze (ed.), National Academy Press, Washington, DC. p. 114-132.

4. Odum, H. T. 1989. Ecological Engineering and self-organization. In: Ecological Engineering: An Introduction to Ecotechnology, W. J. Mitsch and S. E. Jørgensen (eds.). John Wiley \& Sons, NY. p. 79-101.

5. Ma, S. 1988. Development of agro-ecological engineering in China. In: Proceedings of the International Symposium on Agro-Ecological Engineering, August 1988, S. Ma, A. Jiang, R. Xu, and D. Li (eds.). Ecological Society of China, Beijing. p. 1-13.

6. Mitsch, W. J., J. Yan, and J. K. Cronk. 1993. Ecological engineering -- contrasting experiences in China with the West. Ecological Engineering 2:177-191.

7. Miller, P. 1995. Integrity, Sustainability, Biodiversity and Forestry. In: Perspectives on Ecological Integrity, L. Westra and J. Lemons (eds.). Kluwer Academic Publishers, Dordrecht, The Netherlands. p. 218238.

8. Cairns, J., Jr. 1996. Determining the Balance Between Technological and Ecosystem Services. In: Engineering within ecological constraints, P. C. Schulze (ed.), National Academy Press, Washington, DC. p. 12-30.

9. Holling, C. S. 1996. Engineering Resilience versus Ecological Resilience. In: Engineering within ecological constraints, P. C. Schulze (ed.), National Academy Press, Washington, DC. p. 32-45.

10. Leopold, A. 1949. A Sand County almanac and sketches here and there. Oxford Univ. Press, New York. 226 .

11. Walters, C. J. 1986. Adaptive Management of Renewable Resources. McGraw Hill, NY. 374p.

12. Costanza, R. 1996. Designing Sustainable Ecological Economic Systems. In: Engineering within ecological constraints, P. C. Schulze (ed.), National Academy Press, Washington, DC. p. 82-99.

13. Catalano, G. D. 1994. An Ecological Approach to Engineering Education: Recasting Our Relationship to the Earth. In: 1994 Annual Conference Proceedings: American Society for Engineering Education, Washington, DC. p. 2837-2844. 


\section{Biographical Information}

\section{SCOTT BERGEN}

Scott Bergen is a Ph.D. candidate in the forest engineering program at the Univ. of Washington. He received a B.S. in mechanical engineering from Cornell Univ. and an M.S. in forest engineering from the Univ. of Washington. His research interest is the development and application of ecological engineering design principles, particularly to natural resource management.

\section{SUSAN BOLTON}

Susan Bolton is an Associate Professor in Forest Engineering at the Univ. of Washington. She received a Ph.D. in Civil Engineering from New Mexico State Univ. in 1992. She also has degrees in Biology and Ecology from the Univ. of Colorado and North Dakota State Univ. She is a licensed professional engineer in Washington and New Mexico. Her research interests include land use effects on the physical and ecological components of riparian areas and methods of prioritizing restoration projects.

\section{JAMES FRIDLEY}

Jim Fridley is a Professor of Forest Engineering and Mechanical Engineering at the Univ. of Washington. He received a Ph.D. in Mechanical Engineering from the Univ. of Washington, an M.S. in Agricultural Engineering from Michigan State Univ. and a B.S. in Forest Engineering from the Univ. of California at Davis. His interests lie in the methods and theories of engineering design, particularly when applied to the production, processing and stewardship of natural resources. He is licensed professional engineer in the State of Washington. 